\section{Whiplash and Fibromyalgia}

\section{To the Editor:}

Littlejohn and Guymer ${ }^{1}$ attempt to reestablish the nexus between injury and the fibromyalgia syndrome (FMS). Their editorial recommends that "the most important thing is to get the diagnosis right". However, their suggestion that the diagnosis of whiplash is an "emotionally charged" term holds no credibility if they suggest that "fibromyalgia" should be preferred.

Central sensitization has become the first explanatory resort of those seeking to describe virtually any issue relating to chronic pain and the alleged behavioral consequences of mood disturbance and disability. Absent from this discourse is the fact that central sensitization is a reversible phenomenon in virtually all experimental models where an injury occurs as a discrete event. There is no need for epidemiological series to demonstrate this. In competitive contact sports, the full spectrum of physical injuries is seen. Occasionally, serious and permanent disability occurs - almost invariably because of major neurological injury. Despite this, the FM signal remains entirely absent from this domain.

The authors assert that a high proportion of patients with FMS identify a traumatic life event as the trigger for their illness. However, this relies on retrospective data, plagued by recall bias. Prospective population-based studies do not demonstrate the "traumatic" etiology, and baseline psychological distress remains the only recurring predictive factor.

The authors postulate that the paper by Hours, $e t a l^{2}$ demonstrates a link between posttraumatic stress disorder (PTSD) and FMS that sustains central sensitization. Hours' paper makes a "diagnosis" of PTSD at 1 year on questionnaire responses alone. Yet the authors acknowledge an association between those contemplating litigation and the later diagnosis of PTSD. This is not a trivial issue. PTSD is overdiagnosed in litigation, and the ability of lay persons to inflate symptoms of psychological distress (including PTSD) has been well described ${ }^{3,4}$. Further, it seems bold to suggest that the circumstances in which these individuals sustained their minor injuries represent the severely traumatic psychological environment that would yield a high prevalence of chronic PTSD.

Hours, et al recorded the intention to proceed with legal redress at an extremely early stage (apparently with the patients still in hospital) while recording only minimal details of psychological status without assessment of preexisting psychological traits. PTSD symptoms were then recorded at 12 months, but no assessment of the patients' legal status was made, ignoring those patients who later decided to open legal proceedings after discharge from hospital.

Littlejohn and Guymer mention issues of legal causality and dispute, asserting that the secondary consequences of this "may continue to feed the mechanisms of central sensitization". This may suit the zeitgeist of the FM lobby, but ignores even the possibility that the substantial awards made by legal systems act as a perverse incentive in impeding recovery. Surely the principle of parsimony offers the most obvious solution.

Inexplicably, Hours, et al made virtually no mention of their earlier paper looking at the same cohort of patients, but including the full spectrum of injuries ${ }^{5}$ (as well as all of the patients included in the paper published in The Journal of Rheumatology). Their findings regarding medicolegal effects on quality of life were quite clear (it was detrimental) and they felt bold enough to suggest that "undertaking legal action binds the victim to a state of trauma well after the event".

If a combination of physical trauma and PTSD results in FMS, one must ask the question as to where FMS has been lurking in military medicine. Important descriptions of chronic pain states have first been made by military doctors: Paré described phantom limb pain in $1552^{6}$ and Weir-Mitchell, et al described causalgia in $1864^{7}$. Nevertheless, FMS was strikingly absent from the war injury lexicon until it appeared among the group of diagnoses comprising "Gulf War Syndrome". In this case, mere deployment to the region, not trauma or PTSD (which were rare in a conflict that saw very little combat for coalition forces led by the United States), was implicated as causative.

There is, however, potential to learn from military medicine. Following the First World War, tens of thousands of allied troops were diagnosed with the "effort syndrome", a mysterious malady that was confidently linked to "cardiac exhaustion" following overexertion during prolonged combat. Physical treatment failed completely and rest made things worse. The lesson was learned by the time of the Second World War. The diagnosis was abandoned and active rehabilitation close to the combat zone proved far more effective for what was recognized as a psychosomatic affliction ${ }^{8}$.

Rehabilitation from low grade injuries to the cervical spine should prove to be much simpler, unless, of course, plaintiffs' lawyers and their medicolegal advisors succeed in characterizing the phenomenon as an irrecoverable disease of the central nervous system with its attendant assertions of disability and demands for financial compensation. Do Littlejohn and Guymer genuinely believe that the "bad and costly outcomes" they lament elsewhere will improve in this setting?

DILIP KAPUR, FFPMANZCA, Flinders University, School of Medicine, Adelaide, Australia.

Address correspondence to Dr. D. Kapur, Flinders University, School of Medicine, Flinders Drive, Bedford Park, Adelaide, South Australia 5042, Australia.E-mail: dilip.kapur@flinders.edu.au,dkapur@chg.net.au

\section{REFERENCES}

1. Littlejohn GO, Guymer EK. Whiplash: same elephant, different room. J Rheumatol 2014;41:411-3.

2. Hours M, Khati I, Charnay P, Chossegros L, Tardy H, Tournier C, et al. One year after mild injury: comparison of health status and quality of life between patients with whiplash versus other injuries. J Rheumatol 2014;41:528-38.

3. Lees-Haley PR, Dunn JT. The ability of naive subjects to report symptoms of mild brain injury, post traumatic stress disorder, major depression and generalised anxiety disorder. J Clin Psychol 1994;50:252-6.

4. Rosen GM. The Aleutian Enterprise sinking and posttraumatic stress disorder: misdiagnosis in clinical and forensic settings. Prof Psychol Res Pr 1995;26:82-7.

5. Khati I, Hours M, Charnay P, Chossegros L, Tardy H, Hoang-Thy N, et al. Quality of life one year after a road accident: Results from the adult ESPARR cohort. J Trauma Acute Care Surg 2013;74:301-11.

6. Phantom limb pain. Editorial. BMJ 1978;2:1588-9.

7. Weir-Mitchell SW, Morehouse GR, Keen WW. Gunshot wounds and other injuries of nerves. Philadelphia: J.B. Lippincott; 1864.

8. Hyams KC, Wignall S, Roswell R. War syndromes and their evaluation: from the U.S. Civil War to the Persian Gulf War. Ann Intern Med 1996;125:398-405.

J Rheumatol 2014;41:11; doi:10.3899/jrheum.140556 